\title{
Pharmacoeconomics of PCSK9 inhibitors in 103 hypercholesterolemic patients referred for diagnosis and treatment to a cholesterol treatment center
}

Parth Shah*, Charles J. Glueck, Vybhav Jetty, Naila Goldenberg, Matan Rothschild, Rashid Riaz, Gregory Duhon and Ping Wang

\begin{abstract}
Background: PCSK9 inhibitor therapy has been approved by the FDA as an adjunct to diet-maximal tolerated cholesterol lowering drug therapy for adults with heterozygous familial hypercholesterolemia (HeFH) or clinical atherosclerotic cardiovascular disease (ASCVD) with suboptimal LDL cholesterol (LDLC) lowering despite maximal diet-drug therapy. With an estimated $\sim 24$ million of US hypercholesterolemic patients potentially eligible for PCSK9 inhibitors, costing $\sim$ \$14,300/patient/year, it is important to assess health-care savings arising from PCSK9 inhibitors vs ASCVD cost.
\end{abstract}

Methods: In 103 patients with HeFH, and/or ASCVD and/or suboptimal LDLC lowering despite maximally tolerated diet-drug therapy, we assessed pharmacoeconomics of PCSK9 inhibitor therapy with lowering of LDLC. For HeFH diagnosis, we applied Simon Broome's or WHO Dutch Lipid Criteria (score >8). Estimates of direct and indirect costs for ASCVD events were calculated using American Heart Association (AHA), U.S. DHHS, Healthcare Bluebook, and BMC Health Services Research databases. We used the ACC/AHA 10-year ASCVD risk calculator to estimate 10-year ASCVD risk and estimated corresponding direct and indirect costs. Assuming a $50 \%$ reduction in ASCVD events on PCSK9 inhibitors, we calculated direct and indirect health-care savings.

Results: We started 103 patients (58 [56 \%] women and 45 [44 \%] men), on either alirocumab (62\%) or evolocumab (38\%), median age 63, BMI 29.0, and LDLC 149 mg/dl. Of the 103 patients, 28 had both HeFH and ASCVD, 33 with only ASCVD, 33 with only HeFH, and 9 had neither. Of the 103 patients, 61 had a first ASCVD event at median age 55 and on best tolerated cholesterol-lowering therapy median LDLC was 137 mg/dl. In these 61 patients, total direct costs attributable to ASCVD were $\$ 8,904,361(\$ 4,328,623$ direct, $\$ 4,575,738$ indirect), the median 10 -year risk of a new CVD event was calculated to be $13.1 \%$ with total cost $\$ 1,654,758$. Assuming a $50 \%$ reduction in ASCVD events on PCSK9 inhibitors in our 61 patients, $\$ 4,452,180$ would have been saved in the past; and future 10-year savings would be $\$ 1,123,345$.

Conclusion: In the 61 CVD patients, net costs/patient/year were estimated to be $\$ 7,000$ in the past, with future 10 -year intervention net costs/patient/year being $\$ 12,459$, both below the $\$ 50,000 /$ year quality adjusted life-year gained by PCSK9 inhibitor therapy.

(Continued on next page)

\footnotetext{
* Correspondence: prshah06@gmail.com

Supported by Lipoprotein Research Fund; Jewish Hospital of Cincinnati

From the Cholesterol, Metabolism, and Thrombosis Center, Jewish Hospital

of Cincinnati, Cincinnati, USA
} 
(Continued from previous page)

Keywords: PCSK9, Evolocumab, Alirocumab, Cholesterol, Lipids, Pharmacoeconomics, Heterozygous familial hypercholesterolemia (HeFH), Cardiovascular disease (CVD)

\author{
Abbreviations: ACC, American College of Cardiology; AHA, American Heart Association; ASCVD, Atherosclerotic \\ Cardiovascular Disease; BMI, Body Mass Index; CVD, Cardiovascular Disease; FDA, Food and Drug Administration; \\ HDLC, High Density Lipoprotein Cholesterol; HeFH, Heterozgyous Familial Hypercholesterolemia; \\ HoFH, Homozgyous Familial Hypercholesterolemia; LDLC, Low Density Lipoprotein Cholesterol; PVLE, Present Value \\ Life Time Earnings; TC, Total Cholesterol; TG, Triglycerides
}

\section{Background}

Many patients with elevated LDLC fail to achieve treatment targets [1-3], because of statin intolerance [4, 5], expense, lack of insurance coverage, or variations in statin availability across states in insurance, race, and ethnicity [1]. With LDLC lowering potency well beyond statins, PCSK9 inhibitors now offer the promise of optimizing LDLC in a majority of patients with heterozygous familial hypercholesterolemia $(\mathrm{HeFH})$, cardiovascular disease (CVD), and statin intolerance [6-11]. The PCSK9 inhibitor class of medications allows patients to attain LDLC levels that were previously unattainable with maximal diet-drug regimens [6, 10-13]. Preliminary controlled clinical trials, though not powered to assess cardiovascular outcomes, showed approximately a $50 \%$ risk reduction in cardiovascular events $[14,15]$.

Whether and to what degree health care insurers will facilitate approval of PCSK9 class of medications [11, 14, 16 ] at an annual price of $\$ 14,000-14,600$ per patient may ultimately be determined by the outcomes of placebo-controlled trials of hard CVD endpoints and allcause mortality [13] or surrogate CVD endpoints such as regression or non-progression of atherosclerosis by intravascular ultrasound. Overall costs to society also need to include analysis of any potential adverse effects arising from PCSK9 inhibitor use.

Of 734 patients referred to our Cholesterol Center for diagnosis and treatment of high LDLC and/or CVD, with LDLC $\geq 70 \mathrm{mg} / \mathrm{dl}$ despite maximally tolerated cholesterol lowering therapy, we recently reported [17] that $30 \%$ were eligible by FDA [18] and insurance carrier criteria for PCSK9 inhibitor therapy $[11,14,18]$. In the general population of the US [19], the CDC recently reported that $36.7 \%$ (78 million) adults ( $>21$ years) were eligible for cholesterol-lowering medication, but only $55 \%$ were taking a cholesterol lowering medication of whom $\sim 90 \%$ were taking a statin. If $30 \%$ of the 78 million hypercholesterolemic adults in the general US population [19] were, as in our study of hypercholesterolemic subjects [17], eligible by FDA [18] and insurance carrier criteria for PCSK9 therapy, this would include $\sim 11 \%$ of the adult population or 23.4 million adults.
Given current pricing of \$14,000-14,600 per patient per year, annual United States PCSK9 inhibitor costs might approximate $\$ 185-\$ 342$ billion, reflecting the use of an expensive specialty drug for endemic CVD, the leading cause of mortality in the USA [20, 21]. In 2011, annual costs for CVD and stroke were estimated to be $\$ 320.1$ billion [22]. If, speculatively, CVD and stroke incidence could be halved by PCSK9 therapy $[11,14,16]$, direct annual savings would be estimated to be $\$ 160$ billion, and indirect annual savings might be $\$ 85$ billion [21], altogether $\$ 245$ billion savings, in the middle of the range of estimated PCSK9 inhibitor costs of \$185-342 billion [17]. Programs targeted to prevention of CVD should provide substantial overall cost savings [23, 24].

Answers are needed for major questions regarding PCSK9 inhibitor therapy including whether the PCSK9 inhibitors will significantly reduce morbid and mortal CVD events in hypercholesterolemic patients beyond the best currently available diet-statin therapy [25], and whether they will provide an incremental cost-effectiveness ratio [25] within a society willingness-to-pay threshold [26].

In 103 hypercholesterolemic patients, 61 with previous CVD (1st CVD median age 55, median LDLC $139 \mathrm{mg} / \mathrm{dl}$ despite maximal tolerated cholesterol-lowering therapy), we estimated direct + indirect costs of CVD, costs of estimated next 10 year CVD events, and PCSK9 inhibitor costs to assess whether PCSK9s would provide an incremental cost-effectiveness ratio [25] within a society willingness-to-pay threshold [26].

\section{Methods}

The procedures were in accordance with the ethical standards of the responsible committee on human experimentation, approved by the Jewish Hospital Institutional Review Board. The study was carried out with signed informed consent.

Since the commercialization of PCSK9 inhibitors, starting July 2015, we have started 103 patients on either alirocumab or evolocumab. When considering PCSK9 inhibitor therapy, we had two groups of patients based on FDA and insurance criteria with suboptimal LDLC lowering. The first group of patients $(n=31)$ were those who were on 
"maximal-tolerated statin therapy," and also maximum tolerated cholesterol lowering therapy (i.e., colesevelam and/or ezetimibe). The second group of patients $(n=72)$ were those who couldn't tolerate ANY dose of two or more statins and were on maximal tolerated dose of colesevelam and/or ezetimibe. "Maximal tolerated statin therapy" includes not being able to tolerate any statin dose level.

In the 103 patients, we assessed the number approved for coverage either through commercial insurance or Medicare/Medicaid. We further characterized the approved patients based on meeting indications such as $\mathrm{HeFH}$, homozygous familial hypercholesterolemia ( $\mathrm{HoFH})$, and/or CVD or none of the above.

In order to assess for HeFH, we applied Simon Broome's [27] or WHO Dutch Lipid Criteria [28] (score $>8$ ) for $\mathrm{HeFH}$ by tendon xanthomas and LDLC $>190 \mathrm{mg} / \mathrm{dl}$ and/ or family history of premature cardiovascular disease and/ or family history of severe hypercholesterolemia.

At the time of PCSK9 insurance coverage application, before starting PCSK9 therapy, we assessed the following patient characteristics: type and dose of PCSK9 therapy to be started, lipids and lipoprotein cholesterol levels on maximally tolerated diet and lipid lowering drugs, age, gender, BMI (body mass index), previous and current cholesterol lowering therapies, and CVD event age, if applicable. Within the CVD events group, we documented coronary artery disease, acute myocardial infarction, cerebrovascular accidents/stroke, carotid artery disease, and heart failure.

For the 61 patients who had a CVD event, the associated direct and indirect costs before starting PCSK9 therapy were calculated using U.S. Department of Health and Human Services, BMC Health Services Research, and Healthcare Bluebook databases [29-31]. For direct cost calculations, we categorized CVD patients into having coronary artery disease, acute myocardial infarction, stroke/acute cerebrovascular disease, and/or congestive heart failure and calculated average hospitalization costs as per HCUP projections [46]. In our direct cost estimations, we also included the average cost of coronary artery bypass graft, percutaneous angioplasty, carotid endartectomy, and follow-up costs for cardiac diagnostic tests (EKG, stress test, Calcium score), office visits, and cardiac rehabilitation [32]. For indirect costs calculations, we used work absenteeism and short term disability productivity losses over the years after first CVD event [29]. We also applied the present value of lifetime earnings (PVLE) model to calculate indirect costs from premature mortality within the US in our patients based on their age group [33]. We estimated savings in PVLE on PCSK9 using the PCSK9 inhibitor mortality data from Navarese et al. [34].

We used the ACC/AHA 10 year cardiovascular disease risk calculator [35] to estimate likelihood of CVD events within next 10 years, in relevance to the hypercholesterolemic population. A broad cost and benefit to society analysis was done using AHA databases [21, 22].

\section{Results}

To date we have started 103 patients on either alirocumab (62\%) or evolocumab (38\%). Table 1 displays characteristics of this cohort of 103 patients, 58 (56 \%) women and

Table 1 Characteristics of 103 patients started on PCSK9 inhibitor therapy

\begin{tabular}{|c|c|c|c|c|c|c|c|c|c|}
\hline \multirow[b]{2}{*}{$\begin{array}{l}\text { Mean } \pm \text { SD, } \\
\text { Median }\end{array}$} & \multirow[b]{2}{*}{ Race/ Gender } & \multirow[b]{2}{*}{$\begin{array}{l}\text { Statin } \\
\text { intolerant }\end{array}$} & \multirow[b]{2}{*}{$\begin{array}{l}\text { Praluent }(P) / \\
\text { Repatha }(R)\end{array}$} & \multicolumn{6}{|c|}{ Mean \pm SD, Median At Entry } \\
\hline & & & & Age & $\mathrm{BMI}$ & $\mathrm{TC}$ & $\mathrm{TG}$ & HDLC & LDLC \\
\hline All, $N=103$ & $\begin{array}{l}\text { B } 15 \text { (15\%); W } 88 \\
\text { F } 58 \text { (56\%); M } 45\end{array}$ & $73(71 \%)$ & $\begin{array}{l}64(62 \%) P \\
39(38 \%) R\end{array}$ & $62 \pm 10,63$ & $29.6 \pm 5.4,29$ & $250 \pm 59,246$ & $165 \pm 86,142$ & $53 \pm 16,53$ & $166 \pm 55,149$ \\
\hline $\begin{array}{l}\text { CVD, } n=61 \\
1 \text { st CVD } \\
\text { age } 54 \pm 11,55\end{array}$ & $\begin{array}{l}\text { B8 (13\%); W } 53 \\
\text { F } 29 \text { (48\%); M } 32\end{array}$ & $39(64 \%)$ & $\begin{array}{l}42(69 \%) P \\
19(31 \%) R\end{array}$ & $65 \pm 9,66$ & $30.1 \pm 5.1,29.7$ & $234 \pm 56,225$ & $168 \pm 98,139$ & $52 \pm 18,50$ & $150 \pm 51,139$ \\
\hline $\begin{array}{l}\text { HeFH+CVD, } \\
n=28 \\
\text { 1st CVD } \\
\text { age } 53 \pm 12,55\end{array}$ & $\begin{array}{l}\text { B } 7(25 \%) ; \text { W } 21 \\
\text { F } 19(68 \%) ; \text { M } 9\end{array}$ & $16(57 \%)$ & $\begin{array}{l}18(64 \%) P \\
10(36 \%) R\end{array}$ & $59 \pm 11,61$ & $31.5 \pm 5.4,30.9$ & $269 \pm 59,268$ & $159 \pm 77,133$ & $56 \pm 19,54$ & $181 \pm 55,191$ \\
\hline $\begin{array}{l}\text { CVD, no HeFH, } \\
n=33 \\
\text { 1st CVD } \\
\text { age } 55 \pm 11,56\end{array}$ & $\begin{array}{l}\text { B } 1 \text { (3 \%); W } 32 \\
\text { F } 10 \text { (30\%); M23 }\end{array}$ & $23(70 \%)$ & $\begin{array}{l}24(73 \%) P \\
9(27 \%) R\end{array}$ & $65 \pm 10,66$ & $28.8 \pm 4.6,28.7$ & $205 \pm 33,211$ & $177 \pm 113,147$ & $49 \pm 17,47$ & $123 \pm 26,132$ \\
\hline No CVD, $n=42$ & $\begin{array}{l}\text { B } 7 \text { (17\%), W } 35 \\
\text { F } 29 \text { (69\%); M } 13\end{array}$ & $34(81 \%)$ & $\begin{array}{l}22(52 \%) P \\
20(48 \%) R\end{array}$ & $59 \pm 11,59$ & $29.1 \pm 5.9,28.6$ & $272 \pm 56,256$ & $159 \pm 66,155$ & $55 \pm 14,56$ & $187 \pm 53,181$ \\
\hline $\begin{array}{l}\text { HeFH, no CVD, } \\
n=33\end{array}$ & $\begin{array}{l}\text { B } 4 \text { (12\%), W } 29 \\
\text { F } 22 \text { (67\%); M } 11\end{array}$ & $26(79 \%)$ & $\begin{array}{l}18(55 \%) P \\
15(45 \%) R\end{array}$ & $56 \pm 11,57$ & $28.8 \pm 5.6,28.5$ & $284 \pm 58,270$ & $165 \pm 70,156$ & $55 \pm 14,56$ & $198 \pm 54,189$ \\
\hline $\begin{array}{l}\text { No HeFH \& } \\
\text { no CVD, } \\
n=9\end{array}$ & $\begin{array}{l}\text { B } 3(33 \%) ; \text { W6 } \\
\text { F } 7(78 \%) ; \text { M } 2\end{array}$ & $8(89 \%)$ & $\begin{array}{l}4(44 \%) P \\
5(56 \%) R\end{array}$ & $63 \pm 13,64$ & $29.9 \pm 7.0,29.0$ & $231 \pm 15,233$ & $137 \pm 48,154$ & $56 \pm 13,55$ & $148 \pm 17,149$ \\
\hline
\end{tabular}


45 (44 \%) men, with median entry age 63, BMI 29.0, and mean \pm SD LDLC $166 \pm 55 \mathrm{mg} / \mathrm{dl}$ (median 149). Of the 103 patients, 61 had cardiac disease and/or stroke-TIAs during past $10 \pm 9$ years without PCSK9 therapy, Table 1 . Of the 61 patients with cardio-cerebrovascular disease (CVD), 28 had both $\mathrm{HeFH}$ and CVD, and 33 had CVD without $\mathrm{HeFH}$, Table 1 . Of the 42 patients without CVD, 33 had HeFH only, and 9 had neither, Table 1.

In the 103 patients, mean \pm SD 10-year CVD risk calculated from the AHA/ACC calculator was $14.1 \pm$ $12.3 \%$, median $11.3 \%$ (Table 2). In the 61 patients who had sustained a cardiac disease and/or stroke-TIAs before study entry, 10-year calculated CVD risk was $15.9 \pm 11.7 \%$, median $13.1 \%$. In the 42 patients who had no CVD at study entry, the next 10 year calculated CVD risk was $11.5 \pm 12.8 \%$, median $6.8 \%$.

Follow-up lipid and lipoprotein cholesterol levels at 4 weeks on PCSK9 inhibitor therapy, along with diet were available for 94 of the 103 patients and for 56 of the 61 patients with CVD events. Median LDLC in the 94 patients fell from $152 \mathrm{mg} / \mathrm{dl}$ (on maximal tolerated cholesterol lowering therapy without PCSK9 addition) to $76 \mathrm{mg} / \mathrm{dl}$, with the median decrement of LDLC on therapy of $79 \mathrm{mg} / \mathrm{dl}$, percent LDLC drop from baseline $54 \%$ (median) (Table 3). In the 56 patients with CVD disease before study entry, median LDLC fell from $141 \mathrm{mg} / \mathrm{dl}$ at entry to $60 \mathrm{mg} / \mathrm{dl}$, with a median absolute reduction of LDLC by $79 \mathrm{mg} / \mathrm{dl}$, median percent LDLC reduction of $57 \%$ (Table 3). PCSK9 therapy led to a decrement in triglyceride from median $138 \mathrm{mg} / \mathrm{dl}$ to $115 \mathrm{mg} / \mathrm{dl}$, and an increment in HDLC from median $51 \mathrm{mg} / \mathrm{dl}$ to $53 \mathrm{mg} / \mathrm{dl}$, Table 3 .

Of the 103 patients, 61 had a first CVD event at median age of 55 years and median LDLC $139 \mathrm{mg} / \mathrm{dl}$ despite maximal tolerated, non-PCSK9 cholesterollowering therapy, Table 1. As displayed in Fig. 1 (top panel), In the 61 patients with CVD events in the past $10 \pm 9$ years, total direct costs were $\$ 4,328,623$, with estimated total indirect costs $\$ 4,575,738$, with total cost $\$ 8,904,361$. For the 61 patients already having had CVD, future 10-year CVD risk was $15.9 \pm 11.7 \%$, median $13.1 \%$, calculated using the ACC/AHA calculator (which does not depend on subject's CVD event history), Table 2. Without PCSK9, expected CVD events in these
61 patients in the next 10 years were estimated to cost $\$ 1,654,758$, Fig. 1 (top panel), assuming healthcare costs were to stay the same as current.

Using the human capital approach of Menzin et al., [33] we estimated productivity costs as the present value of lifetime earnings (PVLE) lost due to premature mortality, Fig. 1. As displayed in Fig. 1 (top panel), estimated costs of PVLE in the next 10 years in the 61 patients who had already sustained a CVD event was $\$ 712,351$ without PCSK9 inhibitor therapy. Using PCSK9 inhibitors mortality data by Navarese et al. [34], we estimated savings in PVLE on PCSK9 in the next 10 years of \$295,966, Fig. 1 (bottom panel).

Mendelian randomization studies suggest that a lifetime reduction of $\mathrm{LDLC} \sim 40 \mathrm{mg} / \mathrm{dl}$ would reduce risk of ASCVD by $50 \%$ [36]. In our study, after 4 weeks therapy with PCSK9 inhibitors, and beyond maximally tolerated LDLC reduction with diet-statins, median LDLC reduction in the 61 patients with entry CVD was $79 \mathrm{mg} / \mathrm{dl}$, a $57 \%$ reduction (median) from baseline, Table 3. If PCSK9 inhibitors would have reduced ASCVD event rates in the 61 patients with CVD by $50 \%, \$ 4,452,180$ would have been saved (Fig. 1, bottom panel). If PCSK9 inhibitors were used in the next 10 years, assuming a $50 \%$ reduction in CVD events, savings from the 10 year projected CVD cost would be $\$ 827,379$, in addition to the estimated savings by reducing lost PVLE \$295,966, Fig. 1, bottom panel.

In the 61 patients with CVD, PCSK9 therapy costs for 1 year were estimated to be $\$ 872,300$, Fig. 2. If PCSK9 inhibitor therapy had been used in the past, average savings for these 61 patients due to CVD event rates being halved were estimated to be $\$ 445,218$ for 1 year (Fig. 2). Net costs for the 61 patients with CVD, were estimated to be $\$ 427,082$ for 1 year, and net costs per patient per year were estimated to be $\$ 7,000$ (Fig. 2).

Examining 10 years forward for the 61 patients with CVD before entry, PCSK9 costs for the 61 patients for 1 year were $\$ 872,300$, Fig. 3. Average annual savings for 61 patients based on halving the estimated 10-year risk of CVD were estimated to be $\$ 82,738$, and annual savings from otherwise lost PVLE were calculated to be $\$ 29,596$, Fig. 3. As displayed in Fig. 3, for our 61 patients with previous CVD events, adding estimated savings of reduced CVD events (from the ACC/AHA calculator)

Table 2 Estimated $^{a} 10$ year risk of developing a cardiovascular disease (\%)

\begin{tabular}{|c|c|c|c|c|c|c|}
\hline & \multirow[t]{2}{*}{ Mean \pm SD \% } & \multicolumn{5}{|c|}{ Percentiles } \\
\hline & & 10th & 25th & 50th & 75th & 90th \\
\hline All 103 patients & $14.1 \pm 12.3$ & 2.0 & 5.0 & 11.3 & 20.5 & 27.4 \\
\hline 61 patients had CVD event pre study & $15.9 \pm 11.7$ & 3.5 & 7.2 & 13.1 & 21.4 & 27.4 \\
\hline Years since 1st CVD event in the 61 patients & $10.3 \pm 8.9$ & 1.4 & 2.9 & 8.2 & 16.3 & 19.5 \\
\hline 42 patients had no CVD & $11.5 \pm 12.8$ & 1.8 & 3.4 & 6.8 & 18.0 & 21.6 \\
\hline
\end{tabular}

${ }^{\mathrm{a}}$ Estimated using the ACC/AHA calculator 
Table 3 Follow-up lipid and lipoprotein cholesterol levels after 4 weeks on PCSK9 inhibitor therapy, mean \pm SD [median]

\begin{tabular}{|c|c|c|c|c|c|c|}
\hline & Lipids mg/dl & Pre-treatment & $\begin{array}{l}\text { After } 4 \text { weeks on } \\
\text { PCSK9 inhibitor }\end{array}$ & Change (mg/dl) & $\%$ change & $\begin{array}{l}p \text { (paired } \\
\text { Wilcoxon test) }\end{array}$ \\
\hline \multirow{4}{*}{$\begin{array}{l}\text { Of } 103 \text { patients, } 94 \text { at } 4 \text { weeks } \\
\text { follow up }\end{array}$} & $\mathrm{TC}$ & $251 \pm 59[249]$ & $158 \pm 49[159]$ & $-93 \pm 54[-82]$ & $-36 \pm 18 \%[-36 \%]$ & $<.0001$ \\
\hline & $\mathrm{TG}$ & $163 \pm 85[140]$ & $125 \pm 48[119]$ & $-38 \pm 70[-24]$ & $-16 \pm 30 \%[-18 \%]$ & $<.0001$ \\
\hline & HDLC & $54 \pm 16[54]$ & $57 \pm 17[55]$ & $+2 \pm 9[+2]$ & $+6 \pm 15 \%[+4 \%]$ & .0005 \\
\hline & LDLC & $166 \pm 55[152]$ & $77 \pm 43[76]$ & $-89 \pm 50[-79]$ & $-52 \pm 23 \%[-54 \%]$ & $<.0001$ \\
\hline \multirow{4}{*}{$\begin{array}{l}\text { Of } 61 \text { patients with CVD pre } \\
\text { study, } 56 \text { at } 4 \text { weeks follow up }\end{array}$} & $\mathrm{TC}$ & $235 \pm 56[230]$ & $148 \pm 46[146]$ & $-88 \pm 52[-80]$ & $-36 \pm 19 \%[-37 \%]$ & $<.0001$ \\
\hline & $\mathrm{TG}$ & $163 \pm 97[138]$ & $118 \pm 45[115]$ & $-44 \pm 79[-31]$ & $-18 \pm 29 \%[-20 \%]$ & $<.0001$ \\
\hline & HDLC & $54 \pm 18[51]$ & $57 \pm 19[53]$ & $+3 \pm 10[+2]$ & $+7 \pm 17 \%[+5 \%]$ & .002 \\
\hline & LDLC & $151 \pm 51[141]$ & $68 \pm 39[60]$ & $-83 \pm 46[-79]$ & $-54 \pm 24 \%[-57 \%]$ & $<.0001$ \\
\hline
\end{tabular}

and from PVLE, the net cost of PCSK9 therapy was calculated to be $\$ 12,459$ per patient per year, Table 3 .

\section{Discussion}

In the current study, we assessed whether and to what degree PCSK9 inhibitors, as currently priced, would provide an incremental cost-effectiveness ratio (ICER) within a society willingness-to-pay threshold [25, 26], prolonging life, and representing a societal acceptable value. In our 61 patients with CVD at entry, the net cost of PCSK9 inhibitor therapy, assuming a $50 \%$ reduction of CVD events on PCSK9 inhibitor therapy was $\$ 7,000$ per patient, and the net cost of PCSK9 therapy over the next 10 year period was estimated to be $\$ 12,459$ per patient per year, well below the $\$ 50,000$ per year [26] of life saved which has been used to judge value of a pharmacologic therapy. Currently, there is no acceptable model for direct costs of all-cause mortality. Our current ICER shows $\$ 7,000$ with CVD reduction of $50 \%$. If it is assumed that on top of CVD reduction of $50 \%$, all-cause mortality [34] was reduced such that there was $30 \%$ increased savings, then ICER would be $\$ 4900$ and if it was reduced by $60 \%$ then ICER would be $\$ 2800$.

In human health-economics there are two major approaches: the human capital approach, and the friction cost method [37-40]. The friction cost method includes all lost productivity costs due to disease mortality only until the deceased worker is replaced by an unemployed worker [41]. The human capital approach is more widely accepted and recommended as it assumes

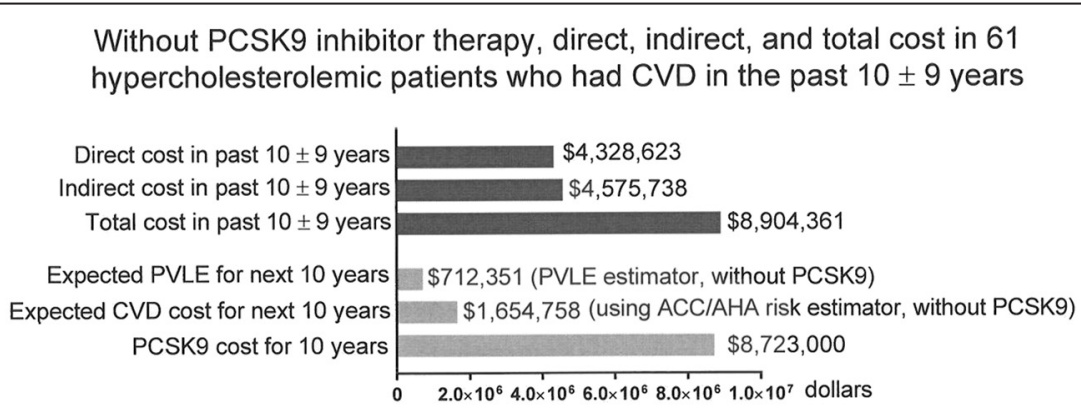

Assume PCSK9 inhibitor therapy was used, reduced CVD events by $50 \%$ and lowered PVLE loss

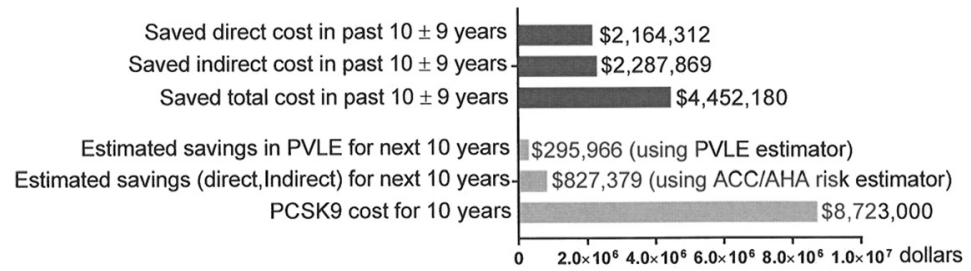

Fig. 1 Top Panel: Total, direct, and indirect costs, expected CVD costs for the next 10 years, and loss of present value of lifetime earnings (PVLE), and costs of PCSK9 inhibitor therapy in 61 hypercholesterolemic patients who had sustained a cardiovascular event (CVD) in the past $10 \pm 9$ years. Bottom Panel: Assume PCSK9 inhibitor therapy was used and reduced CVD events by $50 \%$ and lowered PVLE loss 
Net cost of PCSK9 inhibitor therapy, if PCSK9 inhibitor had reduced CVD by $50 \%$ in 61 CVD patients in the past 10 years, based on their cost history

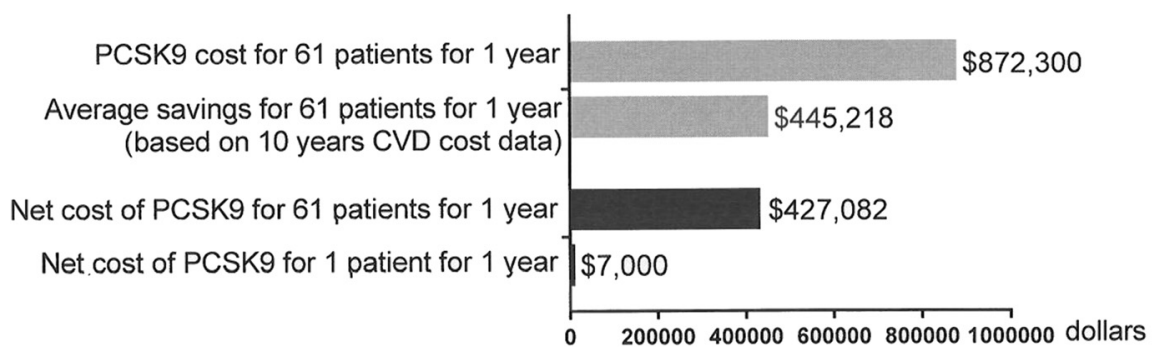

Fig. 2 Net cost of PCSK9 inhibitor therapy, based on 61 patients' cost history, assuming a 50 \% reduction in CVD events on PCSK9 inhibitor therapy

no unemployment, captures all lost productivity due to disease mortality by assuming individuals who died prematurely would have worked full time until the end of their working lives, and includes unpaid labor, such as household work [42-45]. We have used the human capital approach using the model called present value of lifetime earnings (PVLE) to estimate indirect costs due to lost productivity from premature mortality if the patients were not on PCSK9 therapy [33]. Furthermore, the model calculates PVLE based on premature mortality according to age group at death [33]. Presently, direct costs of all-cause mortality cannot be calculated due to lack of acceptable model.

Approximately 735,000 people in US have a myocardial infarction and 795,000 have a stroke each year [20]. Heidenreich et al. project that approximately $41 \%$ of the United States population will have some form of CVD by 2030 [21]. In the MEGA study involving Pravastatin 10 and $20 \mathrm{mg}$ plus diet with follow-up of 5 years, it was demonstrated that CVD risk was reduced by $33-35 \%$. McConnachie et al. randomized 6,595 hypercholesterolemic patients to pravastatin $40 \mathrm{mg}$ or placebo, and followed them for 15 years [46]. Within five years, in the pravastatin $40 \mathrm{mg}$ group there was saving of NHS $£ 710,000$ from CVD related direct costs with gain of 136 quality-adjusted life years [46]. In a rosuvastatin vs. placebo long-term cost effectiveness study with a hypothetical cohort of 100,000 moderate to high risk CVD patients with Framingham risk $\geq 10 \%$, there was QALYs (quality-adjusted life-years) gain of 33,480 over life-time, with 9,916 over 10 years [47]. For a qualityadjusted life year gained, ICER was $\$ 7062$ (lifetime) and $\$ 44,466$ over 10 -years [47]. Montouchet et al. concluded that in a 1,000 member managed care group, statin treatment to goal with rosuvastatin was cost effective, at an additional cost per member per month of only $\$ 0.007$ [48]. Ademi et al. assessed cost of screening for $\mathrm{HeFH}$ and outcomes, assuming a $50 \%$ reduction in events with statins [49]. The ICER ratio was Australian $\$ 4155$ per years of life saved and $\$ 3565$ per QALY gained [49]. Aljutaili et al. discussed cost-effectiveness of a CHD preventative program depending on subjects' risk for CHD, defined as myocardial infarction, stroke or death. They concluded that high risk group would benefit by CHD preventative program (KardioPro) with cost-effectiveness of $€ 20,901-€ 26,456$ per event-free year [50]. Our per year

Net cost of PCSK9 inhibitor therapy, based on ACC/AHA risk calculator, PVLE estimator and 61 CVD patients' cost data, assuming PCSK9 inhibitor therapy reduced CVD events by $50 \%$ and lowered PVLE loss

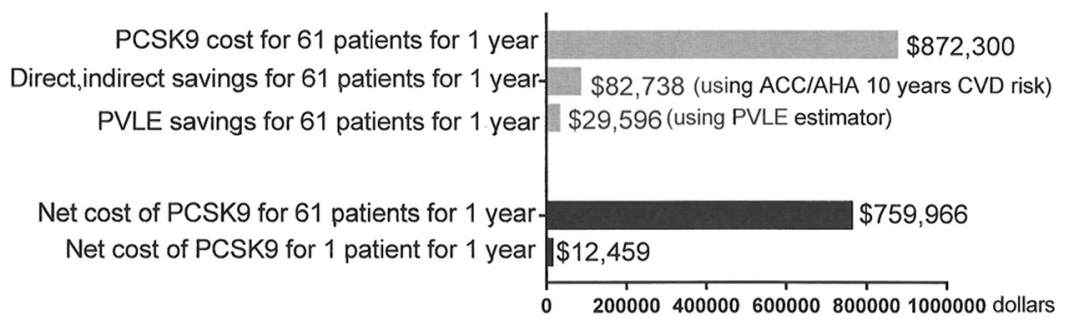

Fig. 3 Net cost of PSCK9 inhibitor therapy, based on CVD events estimated from the ACC/AHA risk calculator and present value of lifetime earnings (PVLE) in 61 patients assuming a $50 \%$ reduction in CVD events and lowered PVLE loss on PCSK9 inhibitor therapy 
cost-effectiveness $\$ 7,000$ falls in between numbers suggested by Ademi et al. of AUD 4155 (USD 3,117) on rosuvastatin therapy and Aljutaili et al. of €26,456 (USD $29,101)$ for high risk/previous CHD event group with all preventative measures.

Statins have been used for 3 decades or more, with the CDC estimating that about $55 \%$ of hypercholesterolemic patients are taking cholesterol lowering therapy, of whom $\sim 90 \%$ are taking statins [19]. Consequently, the American Heart Association estimated that the cost of CVD was $\$ 320.1$ billion in 2011; they further estimate the cost will rise to $\$ 1$ trillion by 2030 [22]. Given the rising healthcare cost burden of CVD, which currently excludes potential savings (as in our current report) of PCSK9 inhibitor use, both secondary and primary prevention of CVD $[24,35]$ will be paramount in the effort to limit the financial burden of CVD on a growing society with limited resources.

Many patients with elevated LDLC cannot achieve treatment targets [1-3] for many reasons [4, 5], while PCSK9 therapy has been shown to be remarkably effective beyond the maximal LDLC lowering achieved by statins [6, 10-13]. In our current study, after maximally tolerated conventional cholesterol lowering therapy, after 4 weeks on PCKS9 inhibitors, median LDLC was decreased to median $79 \mathrm{mg} / \mathrm{dl}$ (54\% decrease) from baseline in 103 patients, and was reduced by median $79 \mathrm{mg} / \mathrm{dl}$ (57 \% decrease) from baseline in the 61 patients with CVD before study entry. Mendelian randomization studies suggest that an approximate $40 \mathrm{mg} / \mathrm{dl}$ drop in LDLC over a lifetime reduces risk of ASCVD by $50 \%[25,36]$. Maintenance of $79 \mathrm{mg} / \mathrm{dl}$ reduction in LDLC observed in the current study should reduce CVD risk by well over $50 \%$.

With the introduction of powerful PCSK9 inhibitors, and as shown in the current study, many patients can regularly meet LDLC targets, $<70 \mathrm{mg} / \mathrm{dl}$ for those with CVD [51], reducing future cardiovascular events by an estimated $50 \%$ or more. Roth et al. reported $73 \%$ reduction in LDLC when alirocumab (150 mg given every 2 weeks) was given with atorvastatin ( $80 \mathrm{mg}$ daily) versus atorvastatin (10 $\mathrm{mg}$ daily) alone [52]. Alirocumab ODYSSEY Phase III studies demonstrated that the mean percentage change in calculated LDLC from baseline to week 24 beyond statin effect was $-61 \%$ (alirocumab) versus $0.8 \%$ (placebo), $p<0.001$ [53]. In 2461 patients treated with alirocumab, 796 (32\%) had two consecutive LDLC levels $<25 \mathrm{mg} / \mathrm{dL}$ while 288 (12\%) had two consecutive LDLC levels $<15 \mathrm{mg} / \mathrm{dL}$ [13]. Furthermore, In the OSLER-1 and OSLER-2 phase III trials, evolocumab reduced LDL cholesterol levels by $-61 \%$ at 12 -week on-treatment median [11] beyond statin effect. In a pool of 2651 evolocumab receiving patients, 1609 (61\%) had at-least one LDLC $<25 \mathrm{mg} / \mathrm{dL}$. Compared to the placebo, there were minimal adverse reactions to the PCSK9 inhibitors with difference between placebo vs. PCSK9 inhibitor group consistently $<2 \%$ [13].

Statin intolerance, predominantly caused by myalgia, myositis, and myopathy occurs in $5 \%$ to $20 \%$ of statintreated patients [54] who will benefit substantially from PCSK9 inhibitor therapy [55]. In the GAUSS-3 study, $43 \%$ of patients on atorvastatin had muscle symptoms and when these patients were enrolled in Phase B, comparing ezetimibe plus placebo vs evolocumab plus placebo, $29 \%$ had myalgias vs $21 \%$ on evolocumab [55]. Furthermore, LDLC reduction from baseline on ezetimibe was 17 vs. $53 \%$ on evolocumab at 24 weeks. In patients with statin intolerance, evolocumab was well tolerated and effective [55].

PCSK9 inhibitor therapy is reserved as an adjunct to diet and maximally tolerated statin therapy for adults with $\mathrm{HeFH}$ or clinical ASCVD requiring additional lowering of LDLC, at a currently listed cost of $\$ 14,000$ $14,600 /$ patient/year. The cost to the society of this drug will rest heavily on the number of people thought to be at high risk with suboptimal cholesterol lowering despite maximally tolerated cholesterol lowering therapy with history of $\mathrm{HeFH}$ [56-58] or CVD [59].

Strengths of our study include documented direct costs of CVD events in hypercholesterolemic patients with CVD, as well as calculated indirect costs, both for CVD events in the past, and projected over the forthcoming 10 years. We have used a PVLE model [33] in order to estimate indirect cost of premature mortality if patients were on or not on PCSK9 therapy [34]. This allowed estimations of net costs per year per patient with patients meeting FDA drug-candidate criteria, and receiving PCSK9 inhibitor therapy with either evolocumab or alirocumab. Our direct cost calculations were limited to average hospital costs of having coronary artery disease, acute myocardial infarction, stroke/acute cerebrovascular disease, congestive heart failure, coronary artery bypass graft, percutaneous angioplasty, carotid endartectomy, and follow-up costs for cardiac diagnostic tests (EKG, stress test, Calcium score), office visits, and cardiac rehabilitation. Another limitation of the study involves use of 10 year ACC/AHA risk calculator [35] which does not include weighting factors for patients age $>80$ years, total cholesterol $>320 \mathrm{mg} / \mathrm{dL}$, or previous history of a CVD event. In the current study, we had 61 patients who had previous CVD events, 13 had total cholesterol $>320 \mathrm{mg} / \mathrm{dL}$, and 1 was older than 80 year. As a group, we speculate that this subcohort's 10 year CVD risk was substantially underestimated by the current estimator. Leening et al. suggest incorporation of soft ASCVD outcomes such as ischemic heart failure, transient ischemic attacks (TIAs), angina, and intermittent claudication in calculations of lifetime risks of 
ASCVD, since a large portion of women and younger individuals suffer from soft ASCVD outcomes [60]. Leening et al. concluded that two-thirds of individuals will develop some form ASCVD over their life span as opposed to one-third dying from ASCVD [60].

\section{Conclusions}

In the $61 \mathrm{CVD}$ patients in our study, net costs would be $\$ 7,000$ /patient/year if PCSK9 had been used in their past, with a $50 \%$ reduction in CVD event rate. For PCSK9 intervention for the future 10 years, net costs were estimated to be $\$ 12,459$ /patient/year, both below the $\$ 50,000 /$ year quality adjusted life-year a benchmark for value of care [26]. As currently priced, we project that PCSK9 inhibitors will provide an incremental costeffectiveness ratio within a society willingness-to-pay threshold [25, 26], prolonging life, and representing a societal acceptable value.

\section{Funding}

Supported in part by the Lipoprotein Research Fund of the Jewish Hospital of Cincinnati.

\section{Author contributions}

Conception and design: PS, CJG, NG. Acquisition of data, editing data: PS, CJG, NG, MR, VJ, RR, GD, PW. Analysis of data: PS, CJG, NG, PW. Drafting the manuscript: PS, CJG, NG, VJ, PW. Given approval for final manuscript: PS, CJG, $N G, V J, R R, M R$, GD, PW. Agree to be accountable: PS, CJG, NG, VJ, RR, MR, $\mathrm{GD}, \mathrm{PW}$

\section{Competing interests}

The authors declare that they have no competing interests.

\section{Consent for publication}

Not applicable.

\section{Ethics approval and consent to participate}

The procedures were in accordance with the ethical standards of the responsible committee on human experimentation, approved by the Jewish Hospital Institutional Review Board. The study was carried out with signed informed consent.

Received: 21 May 2016 Accepted: 9 August 2016

Published online: 18 August 2016

\section{References}

1. Hsia SH, Desnoyers ML, Lee ML. Differences in cholesterol management among states in relation to health insurance and race/ethnicity across the United States. J Clin Lipidol. 2013;7(6):675-82.

2. Mann D, Reynolds K, Smith D, Muntner P. Trends in statin use and lowdensity lipoprotein cholesterol levels among US adults: impact of the 200 National Cholesterol Education Program guidelines. Ann Pharmacother. 2008;42(9):1208-15.

3. Waters DD, Brotons C, Chiang CW, Ferrieres J, Foody J, Jukema JW, et al. Lipid treatment assessment project 2: a multinational survey to evaluate the proportion of patients achieving low-density lipoprotein cholesterol goals. Circulation. 2009;120(1):28-34.

4. Glueck CJ, Budhani SB, Masineni SS, Abuchaibe C, Khan N, Wang P, et al. Vitamin $\mathrm{D}$ deficiency, myositis-myalgia, and reversible statin intolerance. Curr Med Res Opin. 2011;27(9):1683-90.

5. Khayznikov M, Hemachrandra K, Pandit R, Kumar A, Wang P, Glueck CJ. Statin Intolerance Because of Myalgia, Myositis, Myopathy, or Myonecrosis Can in Most Cases be Safely Resolved by Vitamin D Supplementation. N Am J Med Sci. 2015;7(3):86-93.

6. Robinson JG, Kastelein JJ. PCSK9 Inhibitors and Cardiovascular Events. N Engl J Med. 2015;373(8):774.
7. Sabatine MS, Wasserman SM, Stein EA. PCSK9 Inhibitors and Cardiovascular Events. N Engl J Med. 2015:373(8):774-5.

8. Shrank WH, Barlow JF, Brennan TA. New Therapies in the Treatment of High Cholesterol: An Argument to Return to Goal-Based Lipid Guidelines. JAMA. 2015;314(14):1443-4.

9. Stein EA, Raal FJ. Lipid-Lowering Drug Therapy for CVD Prevention: Looking into the Future. Curr Cardiol Rep. 2015;17(11):104.

10. Everett BM, Smith RJ, Hiatt WR. Reducing LDL with PCSK9 Inhibitors-The Clinical Benefit of Lipid Drugs. N Engl J Med. 2015;373(17):1588-91.

11. Gouni-Berthold I, Descamps OS, et al. Systematic review of published phase 3 data on anti-PCSK9 monoclonal antibodies in patients with hypercholesterolaemia. Br J Clin Pharamacol. 2016. doi:10.1111/bcp.13066.

12. Lepor NE, Kereiakes DJ. The PCSK9 Inhibitors: A Novel Therapeutic Target Enters Clinical Practice. Am Health Drug Benefits. 2015;8(9):483-9.

13. Lipinski MJ, Benedetto U, Escarcega RO, Biondi-Zoccai G, Lhermusier T, Baker NC, et al. The impact of proprotein convertase subtilisin-kexin type 9 serine protease inhibitors on lipid levels and outcomes in patients with primary hypercholesterolaemia: a network meta-analysis. Eur Heart J. 2016:37(6):536-45.

14. Robinson JG, Farnier M, Krempf M, Bergeron J, LuC G, Averna M, et al. Efficacy and safety of alirocumab in reducing lipids and cardiovascular events. N Engl J Med. 2015;372(16):1489-99.

15. Sabatine MS, Giugliano RP, Wiviott SD, Raal FJ, Blom DJ, Robinson J, et al. Efficacy and safety of evolocumab in reducing lipids and cardiovascular events. N Engl J Med. 2015;372(16):1500-9.

16. Zhang $X L$, Zhu QQ, Zhu L, Chen JZ, Chen QH, Li GN, et al. Safety and efficacy of anti-PCSK9 antibodies: a meta-analysis of 25 randomized, controlled trials. BMC Med. 2015;13:123.

17. Glueck CJ, Shah P, Goldenberg N, Prince M, Lee K, Jetty V, et al. Eligibility for PCSK9 treatment in 734 Hypercholesterolemic patients referred to a regional cholesterol treatment center with $\mathrm{LDL}$ cholesterol $>/=70 \mathrm{mg} /$ dl despite maximal tolerated cholesterol lowering therapy. Lipids Health Dis. 2016;15(1):55

18. Food and Drug Administration. Praluent (alirocumab): prescribing information. 2015. Available from: http://www.accessdata.fda.gov/drugstfda_ docs/label/2015/1255590rig1s000lbl.pdf. Accessed 15 May 2016.

19. Mercado C, DeSimone AK, Odom E, Gillespie C, Ayala C, Loustalot F. Prevalence of Cholesterol Treatment Eligibility and Medication Use Among Adults - United States, 2005-2012. MMWR Morb Mortal Wkly Rep. 2015; 64(47):1305-11.

20. Mozaffarian D, Benjamin EJ, Go AS, Arnett DK, Blaha MJ, Cushman M, et al. Heart disease and stroke statistics-2015 update: a report from the American Heart Association. Circulation. 2015;131(4):e29-e322.

21. Heidenreich PA, Trogdon JG, Khavjou OA, Butler J, Dracup K, Ezekowitz MD, et al. Forecasting the future of cardiovascular disease in the United States: a policy statement from the American Heart Association. Circulation. 2011; 123(8):933-44.

22. Weintraub WS, Daniels SR, Burke LE, Franklin BA, Goff Jr DC, Hayman LL, et al. Value of primordial and primary prevention for cardiovascular disease: a policy statement from the American Heart Association. Circulation. 2011; 124(8):967-90

23. Milani RV, Lavie CJ. Impact of worksite wellness intervention on cardiac risk factors and one-year health care costs. Am J Cardiol. 2009:104(10):1389-92.

24. Arena R, Guazzi M, Briggs PD, Cahalin LP, Myers J, Kaminsky LA, et al. Promoting health and wellness in the workplace: a unique opportunity to establish primary and extended secondary cardiovascular risk reduction programs. Mayo Clin Proc. 2013;88(6):605-17.

25. Weintraub WS, Gidding SS. PCSK9 Inhibitors: A Technology Worth Paying For? Pharmacoeconomics. 2016;34(3):217-20.

26. Neumann PJ, Cohen JT, Weinstein MC. Updating cost-effectiveness-the curious resilience of the $\$ 50,000-$ per-QALY threshold. N Engl J Med. 2014;371(9):796-7.

27. Marks D, Thorogood M, Neil HA, Humphries SE. A review on the diagnosis, natural history, and treatment of familial hypercholesterolaemia. Atherosclerosis. 2003;168(1):1-14.

28. Austin MA, Hutter CM, Zimmern RL, Humphries SE. Genetic causes of monogenic heterozygous familial hypercholesterolemia: a HuGE prevalence review. Am J Epidemiol. 2004:160(5):407-20.

29. Song X, Quek RG, Gandra SR, Cappell KA, Fowler R, Cong Z. Productivity loss and indirect costs associated with cardiovascular events and related clinical procedures. BMC Health Serv Res. 2015;15:245. 
30. Steiner C, Barrett M, Weiss A. HCUP Projections: Cardiovascular/ Cerebrovascular Conditions and Procedures 2001 to 2012. HCUP Projections Report \#2012-02. 2012

31. "Find Your Fair Price." [database on the Internet]. CareOperative. 2016 [cited April 15 2016]. Available from: https://healthcarebluebook.com/. Accessed 12 Aug 2016

32. Yu CM, Lau CP, Chau J, McGhee S, Kong SL, Cheung BM, et al. A short course of cardiac rehabilitation program is highly cost effective in improving long-term quality of life in patients with recent myocardial infarction or percutaneous coronary intervention. Arch Phys Med Rehabil. 2004;85(12):1915-22.

33. Menzin J, Marton JP, Menzin JA, Willke RJ, Woodward RM, Federico V. Lost productivity due to premature mortality in developed and emerging countries: an application to smoking cessation. BMC Med Res Methodol. 2012;12:87.

34. Navarese EP, Kolodziejczak M, Schulze V, Gurbel PA, Tantry U, Lin Y, et al. Effects of Proprotein Convertase Subtilisin/Kexin Type 9 Antibodies in Adults With Hypercholesterolemia: A Systematic Review and Meta-analysis. Ann Intern Med. 2015;163(1):40-51.

35. Cook NR, Ridker PM. Further insight into the cardiovascular risk calculator: the roles of statins, revascularizations, and underascertainment in the Women's Health Study. JAMA Intern Med. 2014;174(12):1964-71.

36. Ference BA, Yoo W, Alesh I, Mahajan N, Mirowska KK, Mewada A, et al. Effect of long-term exposure to lower low-density lipoprotein cholesterol beginning early in life on the risk of coronary heart disease: a Mendelian randomization analysis. J Am Coll Cardiol. 2012;60(25):2631-9.

37. Brouwer WB, Koopmanschap MA. The friction-cost method: replacement for nothing and leisure for free? Pharmacoeconomics. 2005;23(2):105-11.

38. Hutubessy RC, van Tulder MW, Vondeling H, Bouter LM. Indirect costs of back pain in the Netherlands: a comparison of the human capital method with the friction cost method. Pain. 1999;80(1-2):201-7.

39. Koopmanschap MA, Rutten FF. A practical guide for calculating indirect costs of disease. Pharmacoeconomics. 1996;10(5):460-6.

40. Koopmanschap MA, Rutten FF, van Ineveld BM, van Roijen L. The friction cost method for measuring indirect costs of disease. J Health Econ. 1995;14(2):171-89.

41. Lofland JH, Locklear JC, Frick KD. Different approaches to valuing the lost productivity of patients with migraine. Pharmacoeconomics. 2001;19(9):917-25.

42. Grosse SD, Krueger KV, Mvundura M. Economic productivity by age and sex: 2007 estimates for the United States. Med Care. 2009:47(7 Suppl 1):S94-S103.

43. Liljas B. How to calculate indirect costs in economic evaluations. Pharmacoeconomics. 1998;13(1 Pt 1):1-7.

44. Rasmussen SR, Prescott E, Sorensen TI, Sogaard J. The total lifetime health cost savings of smoking cessation to society. Eur J Public Health. 2005;15(6):601-6.

45. Zhang W, Bansback N, Anis AH. Measuring and valuing productivity loss due to poor health: A critical review. Soc Sci Med. 2011;72(2):185-92.

46. McConnachie A, Walker A, Robertson M, Marchbank L, Peacock J, Packard CJ, et al. Long-term impact on healthcare resource utilization of statin treatment, and its cost effectiveness in the primary prevention of cardiovascular disease: a record linkage study. Eur Heart J. 2014;35(5):290-8.

47. Ohsfeldt RL, Gandhi SK, Smolen L, Jensen MM, Fox KM, Gold A, et al. Cost effectiveness of rosuvastatin in patients at risk of cardiovascular disease based on findings from the JUPITER trial. J Med Econ. 2010;13(3):428-37.

48. Montouchet C, Ruff L, Balu S. Budget impact of rosuvastatin initiation in high-risk hyperlipidemic patients from a US managed care perspective. J Med Econ. 2013;16(7):907-16

49. Ademi Z, Watts GF, Pang J, Sijbrands EJ, van Bockxmeer FM, O'Leary P, et al. Cascade screening based on genetic testing is cost-effective: evidence for the implementation of models of care for familial hypercholesterolemia. J Clin Lipidol. 2014;8(4):390-400.

50. Aljutaili M, Becker C, Witt S, Holle R, Leidl R, Block M, et al. Should health insurers target prevention of cardiovascular disease? A cost-effectiveness analysis of an individualised programme in Germany based on routine data. BMC Health Serv Res. 2014;14:263

51. Grundy SM, Cleeman Jl, Merz CN, Brewer Jr HB, Clark LT, Hunninghake DB, et al. Implications of recent clinical trials for the National Cholesterol Education Program Adult Treatment Panel III guidelines. Circulation. 2004;110(2):227-39.
52. Roth EM, McKenney JM, Hanotin C, Asset G, Stein EA. Atorvastatin with or without an antibody to PCSK9 in primary hypercholesterolemia. N Engl J Med. 2012;367(20):1891-900.

53. Roth EM. Alirocumab for hyperlipidemia: ODYSSEY Phase III clinical trial results and US FDA approval indications. Future Cardiol. 2016;12(2):115-28.

54. Stroes ES, Thompson PD, Corsini A, Vladutiu GD, Raal FJ, Ray KK, et al. Statin-associated muscle symptoms: impact on statin therapy-European Atherosclerosis Society Consensus Panel Statement on Assessment, Aetiology and Management. Eur Heart J. 2015;36(17):1012-22.

55. Nissen SE, Stroes E, Dent-Acosta RE, Rosenson RS, Lehman SJ, Sattar N, et al. Efficacy and Tolerability of Evolocumab vs Ezetimibe in Patients With Muscle-Related Statin Intolerance: The GAUSS-3 Randomized Clinical Trial. JAMA. 2016;315(15):1580-90.

56. Elshazly MB, Martin SS, Blaha MJ, Joshi PH, Toth PP, McEvoy JW, et al. Non-high-density lipoprotein cholesterol, guideline targets, and population percentiles for secondary prevention in 1.3 million adults: the VLDL-2 study (very large database of lipids). J Am Coll Cardiol. 2013;62(21):1960-5.

57. Fryar CD, Chen TC, Li X. Prevalence of uncontrolled risk factors for cardiovascular disease: United States, 1999-2010. NCHS Data Brief. 2012;103:1-8

58. Toth PP, Potter D, Ming EE. Prevalence of lipid abnormalities in the United States: the National Health and Nutrition Examination Survey 2003-2006. J Clin Lipidol. 2012;6(4):325-30

59. Grundy SM, Cleeman JI, Merz CN, Brewer Jr HB, Clark LT, Hunninghake DB, et al. Implications of recent clinical trials for the National Cholesterol Education Program Adult Treatment Panel III Guidelines. J Am Coll Cardiol. 2004:44(3):720-32.

60. Leening MJ, Berry JD, Allen NB. Lifetime Perspectives on Primary Prevention of Atherosclerotic Cardiovascular Disease. JAMA. 2016;315(14):1449-50.

\section{Submit your next manuscript to BioMed Central and we will help you at every step:}

- We accept pre-submission inquiries

- Our selector tool helps you to find the most relevant journal

- We provide round the clock customer support

- Convenient online submission

- Thorough peer review

- Inclusion in PubMed and all major indexing services

- Maximum visibility for your research

Submit your manuscript at www.biomedcentral.com/submit 